\title{
Diminished Viability, Growth, and Behavioral Efficacy of Fetal Dopamine Neuron Grafts in Aging Rats with Long-Term Dopamine Depletion: An Argument for Neurotrophic Supplementation
}

\author{
Timothy J. Collier, Caryl E. Sortwell, and Brian F. Daley \\ Department of Neurological Sciences and Research Center for Brain Repair, Rush Presbyterian-St. Luke's Medical \\ Center, Chicago, Illinois 60612
}

\begin{abstract}
We examined the behavioral and morphological correlates of the response to a single intrastriatal dispersed cell graft of fetal rat ventral mesencephalic tissue in male Fischer-344 rats of varying age (4, 17, and 24-26 months old) and history of mesostriatal dopamine (DA) depletion (1 or 14 months). Our goal was to determine the impact of advancing age and duration of DA depletion in the host on DA graft viability and function. The findings can be summarized as follows. (1) Fetal DA neuron grafts that were effective in completely ameliorating amphetamine-induced rotational behavior in young rats with short-term lesions were virtually without effect in aged rats with long-term lesions. Middle-aged rats with long-term lesions responded to these grafts with partial behavioral recovery. (2) Age of the host at the time of transplantation, and not duration of DA depletion, was the primary determinant of response to DA
\end{abstract}

grafts. (3) Diminished efficacy of grafts in lesioned aging rats was related to decreased survival and neurite extension of transplanted DA neurons. (4) Co-grafts of DA neurons with Schwann cells as a source of neurotrophic support improved the behavioral outcome of grafts in aged lesioned rats. These findings support the view that the DA-depleted striatum of aged rats is an impoverished environment for survival, growth, and function of DA grafts. Consistent with this view, local supplementation of the neurotrophic environment of grafted DA neurons with products of co-grafted Schwann cells, a demonstrated source of neurotrophic activity for embryonic DA neurons, improved graft outcome.

Key words: dopamine; fetal; transplant; graft; aging; neurotrophic; long-term lesion; co-graft; Schwann cells; Parkinson's disease; rotational behavior; amphetamine; striatum
Transplantation of embryonic dopamine (DA) neurons currently is being evaluated as an experimental replacement therapy for Parkinson's disease (PD). Many years of successful research on neural grafting in animal models of PD (Brundin et al., 1987; Yurek and Sladek, 1990) have led to clinical trials (Olanow et al., 1996). Animal models have had significant predictive value because survival of large numbers of grafted DA neurons has been verified in some PD patients (Kordower et al., 1996), serial PET scans suggest increased striatal DA tone after transplants (Freed et al., 1992; Spencer et al., 1992; Kordower et al., 1995), and meaningful clinical benefit has been reported (Widner et al., 1992; Freeman et al., 1995). Despite these encouraging findings, relative survival of grafted DA neurons in humans is low (5$10 \%$ ), and improvement of behavioral symptoms is incomplete. Consequently, for neural grafting to become an important treatment option for PD, limitations of the approach must be identified and graft outcome must be improved.

Part of the disparity between experimental success in animals and the mixed outcome in human trials may be that animal models of PD have failed to examine certain characteristics of potential recipients of graft therapy that impact significantly on the environment of grafted cells. Two such characteristics are the

Received Jan. 25, 1999; revised April 2, 1999; accepted April 8, 1999.

This work was supported by National Institute on Aging Grant AG10851. We gratefully acknowledge the contributions of Dr. Kathy Steece-Collier and Dr. Glenn Stebbins.

Correspondence should be addressed to Dr. Timothy J. Collier, Department of Neurological Sciences, Rush Presbyterian Medical Center, Tech 2000, Suite 200, 2242 West Harrison Street, Chicago, IL 60612.

Copyright (C) 1999 Society for Neuroscience $\quad 0270-6474 / 99 / 195563-11 \$ 05.00 / 0$ chronological age of the transplant recipient and the effects of a long history of striatal DA depletion. In general, PD is a disease of aging, and the majority of affected individuals are over the age of 60 years. In addition, the time course of neural degeneration in $\mathrm{PD}$ is protracted, proceeding for years before symptoms are detected and therapy is initiated. The majority of transplantation studies in animals have used young adults, with experimentally induced DA depletions in place for a few months at most. Experimental results derived from implantation of embryonic neurons into this relatively optimal environment may have raised overly optimistic expectations of clinical efficacy.

The combined factors of advanced age and long history of DA depletion have not been modeled in animal experiments of DA neuron grafting. The mesostriatal DA system is known to undergo various changes in presynaptic (Joseph et al., 1978; Ponzio et al., 1982; Strong et al., 1982; Morgan and Finch, 1988; Hebert and Gerhardt, 1998; Yurek et al., 1998) and postsynaptic (Joseph et al., 1978; Memo et al., 1980; Joseph et al., 1981; Misra et al., 1981; Morgan and Finch, 1988; Valerio et al., 1994) function during aging. Superimposing profound loss of nigral neurons on these aging changes may influence the environment of grafted DA neurons in ways that are difficult to predict. An additional concern is the nature of the neurotrophic environment for grafted neurons in the aged DA-depleted striatum. Identified growth factors for DA neurons are present in diminished quantity or absent in the adult and aging organism (Wilcox and Derynck, 1988; Schaar et al., 1993; Seroogy et al., 1993; Stromberg et al., 1993; Choi-Lundberg and Bohn, 1995; Nosrat et al., 1996; Kornblum et al., 1997; Widenfalk et al., 1997; Collier and Sortwell, 1999). Thus, the potential exists that the aged lesioned striatum 
STY

STM

Figure 1. Experimental design. Figure summarizes the age of rats at time of mesostriatal lesion, tissue transplantation, and perfusion for brain collection. STY, Short-term lesion (1 month duration) in young adult rats (4 m.o. at time of transplant); STM, shortterm lesion (1 month) in middle-aged rats (17 m.o. at time of transplant); LTM, long-term lesion (14 month duration) in middle-aged rats (17 m.o. at time of transplant); STO, short-term lesion (1 month) in aged rats (24 m.o. at time of transplant); LTO, long-term lesion (14 months) in aged rats (26 m.o. at time of transplant). m.o., Months old (age).

LTM

STO

LTO
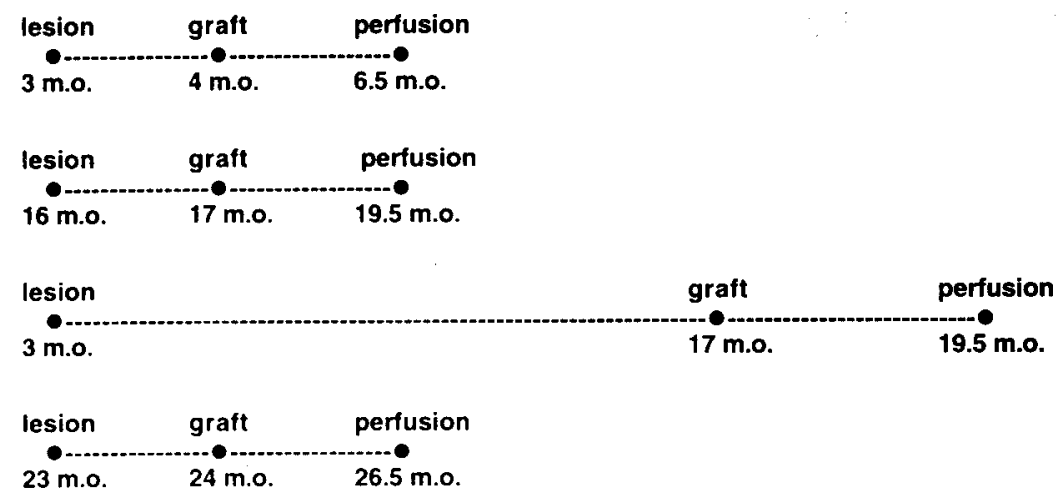

represents an impoverished environment for grafted DA neurons that may contribute directly to diminished graft survival and growth in individuals of advanced age.

In the present study we have held the composition and target of the embryonic DA neuron graft constant and have systematically varied features of the host environment. In particular, we compared the behavioral effects and morphological features of DA neuron grafts in rats of middle-age [17 months old (m.o.)] and advanced age (26 m.o.) with a long history of unilateral mesostriatal DA depletion (14 months) with reference groups of 4, 17, and 24 m.o. rats with lesions in place for 1 month before grafting. In addition, we provide evidence that the neurotrophic environment of grafted DA neurons may be a crucial variable in aged hosts by comparing the effects of DA neurons co-grafted with Schwann cells, a source of neurotrophic support for embryonic DA neurons (Collier et al., 1990; Collier and Springer, 1991; Collier and Martin, 1993), with grafts of DA neurons alone.

\section{MATERIALS AND METHODS}

Experimental animals. Adult male Fischer-344 rats were studied. A total of 30 rats at 3 months of age and 36 rats at 12 months of age were originally assigned to long-term lesion experiments. These rats received large unilateral lesions of the mesostriatal DA pathway and 14 months later were assigned to experimental groups for neural grafting. At the time of transplant surgery, 23 of the younger animals, now 17 months of age, had survived, and 15 of the older animals, now 26 months of age, had survived. The behavioral and morphological data reported are derived from these populations of survivors. For comparison of graft outcomes, three additional groups of rats were studied, all receiving large unilateral mesostriatal lesions 1 month before surgery for neural transplantation: 10 rats at 4 m.o., 12 rats at 17 m.o., and 15 rats at 24 m.o. The experimental design is summarized in Figure 1. Care and use of these animals was in compliance with all applicable laws and regulations as well as principles expressed in the National Institutes of Health, United States Public Health Service Guide for the Care and Use of Laboratory Animals. This study was approved by the Animal Care and Use Committee of Rush PresbyterianSt. Luke's Medical Center.

Mesostriatal lesion. All rats received large, unilateral, right hemisphere lesions of the mesostriatal DA pathway. 6-Hydroxydopamine (RBI, Natick, MA) was infused at a concentration of $10 \mu \mathrm{g} / 2 \mu \mathrm{l}$ of $0.2 \%$ ascorbic acid-physiological saline solution into each of two sites: the mesostriatal fiber bundle $(4.3 \mathrm{~mm}$ caudal to bregma, $1.2 \mathrm{~mm}$ lateral to midline, and $7.5 \mathrm{~mm}$ below dura) and the rostral substantia nigra $(4.8 \mathrm{~mm}$ caudal to bregma, $1.7 \mathrm{~mm}$ lateral to midline, $7.5 \mathrm{~mm}$ below dura). Coordinates were from Paxinos and Watson (1986).

Behavioral testing. All rats were tested for rotational behavior in response to amphetamine challenge ( $5 \mathrm{mg} / \mathrm{kg}$, i.p.). Animals were tested at baseline and 1 or 14 months after lesion and before surgery for neural grafting, and again at 3, 5, 7, and 9 weeks after grafting. Rotational behavior was assayed in a computer-assisted rotometer system that tabulated the number of complete $360^{\circ}$ ipsilateral and contralateral whole-body turns in 5 min intervals over a 90 min test session after amphetamine administration. Behavioral tests commenced 5-10 min after drug injection. Results of rotational behavior tests were expressed as net ipsilateral rotations per minute (number of ipsilateral rotations number of contralateral rotations $/ 90 \mathrm{~min}$ ).

Transplant surgery. At 14 months or 1 month after lesion of the ascending DA pathway, rats received either an intrastriatal tissue graft or served as unoperated controls for behavioral testing. Young and middleaged rats with short-term lesions received a single implant of dissociated ventral mesencephalic (VM) tissue, or no treatment. Middle-aged rats with long-term lesions and aged rats with long- or short-term lesions received an implant of VM tissue, a co-graft of VM tissue plus dissociated sciatic nerve Schwann cells, or no treatment. The composition and target of all grafts was held constant, as were protocols for preparation and implantation of the tissue. Briefly, VM tissue was pooled in calciummagnesium-free (CMF) buffer, incubated in $0.125 \%$ trypsin at $37^{\circ} \mathrm{C}$ for $10 \mathrm{~min}$ with intermittent agitation, rinsed, triturated, pelleted through fetal calf serum by centrif ugation at $800 \mathrm{rpm}$ for $10 \mathrm{~min}$, and adjusted for cell number in CMF buffer. For co-grafts, sciatic nerves from 3-d-old rat pups were pooled in CMF buffer, incubated in $0.13 \%$ collagenase at $37^{\circ} \mathrm{C}$ for 10 min with intermittent agitation, reincubated in a combination of collagenase and $0.125 \%$ trypsin at $37^{\circ} \mathrm{C}$ for an additional $20 \mathrm{~min}$, rinsed, triturated, pelleted through fetal calf serum by centrifugation at $800 \mathrm{rpm}$ for $10 \mathrm{~min}$, and adjusted for cell number in CMF buffer. VM grafts consisted of 120,000 cells in $2 \mu \mathrm{l}$ of CMF buffer infused into a single site in the center of the striatum $(0.7 \mathrm{~mm}$ rostral to bregma, $2.5 \mathrm{~mm}$ lateral to midline, $5.0 \mathrm{~mm}$ below dura). Schwann cell co-grafts consisted of 375,000 cells in $5 \mu \mathrm{l}$ aimed at the striatum $1.0 \mathrm{~mm}$ lateral to the VM implant $(0.7$ $\mathrm{mm}$ rostral to bregma, $3.5 \mathrm{~mm}$ lateral to midline, $5.0-6.0 \mathrm{~mm}$ below dura). All implants were infused via a $10 \mu \mathrm{l}$ Hamilton syringe. Rats receiving only the $\mathrm{VM}$ implant received passage of an empty needle at the same coordinates as the sciatic nerve suspension to control for effects of tissue damage.

Histology. At the conclusion of behavioral tests, rats were deeply anesthetized and perfused intracardially with physiological saline followed by ice-cold $4 \%$ buffered paraformaldehyde. After immersion in $20 \%$ sucrose solution, brains were sectioned on a freezing microtome at a thickness of $35 \mu \mathrm{m}$ and collected in storage trays filled with cryoprotectant solution. Immunocytochemistry for tyrosine hydroxylase (TH) was performed on sections at $70 \mu \mathrm{m}$ intervals and used as a marker for DA neurons and their processes. Mouse anti-TH monoclonal antibody (Chemicon International, Temecula, CA) was used at a dilution of 1:4000, and tissue was processed according to the Vectastain ABC protocol (Vector Laboratories, Burlingame, CA). Additional sections were stained for Nissl substance to assess general morphology of VM and sciatic nerve Schwann cell grafts. Only some grafted rats from which behavioral data were collected were processed for immunocytochemical analysis. Some dropouts occurred because of death from age-related natural causes; other brains, including all unoperated controls, were collected in a manner compatible with other analyses and devoted to a separate study. 

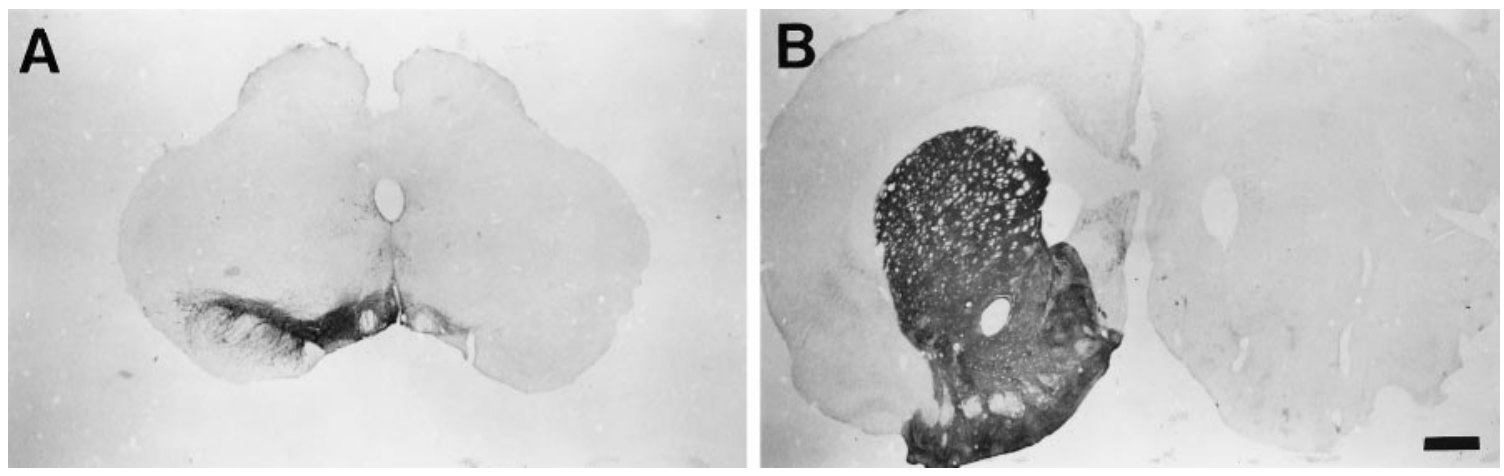

Figure 2. Representative unilateral mesostriatal lesion. Tyrosine hydroxylase $(\mathrm{TH})$ staining at the level of the substantia nigra pars compacta $(A)$ and caudate nucleus $(B)$. Lesions in all experimental groups produced near-complete loss of $\mathrm{TH}^{+}$neurons from the substantia nigra pars compacta and fibers in the ipsilateral caudate nucleus. There was additional severe depletion of $\mathrm{TH}^{+}$soma in the ventral tegmental area and associated innervation of terminal fields. Scale bar, $1.0 \mathrm{~mm}$.

Quantitation of morphology. Four characteristics of grafted fetal VM tissue were evaluated with quantitative morphology: (1) relative number of surviving grafted $\mathrm{TH}^{+}$neurons from cell counts at constant section interval, (2) total size of the tissue graft as represented by rostral-caudal extent, (3) cross-sectional area of grafted $\mathrm{TH}^{+}$elements, including grafted $\mathrm{TH}^{+}$neurons and their processes, and (4) relative density of graft-derived $\mathrm{TH}^{+}$innervation in the host striatum immediately adjacent to the tissue graft. $\mathrm{TH}^{+}$neuronal soma were counted in VM grafts to provide comparisons of relative survival of grafted DA neurons across experimental conditions. Cell counts were made at $70 \mu \mathrm{m}$ intervals. A cell had to exhibit at least one neurite or have a visible nucleus to be included in cell counts. Total size of VM grafts was assessed by simply tabulating the presence of grafted tissue in serial sections. Section number was multiplied by section interval and section thickness to arrive at a relative value for graft size in the rostral-caudal dimension. Crosssectional area of grafted $\mathrm{TH}^{+}$elements (neurons + innervation) and intensitometric measurements of $\mathrm{TH}^{+}$fiber density in the grafted striatum immediately adjacent to grafts were made using computer-assisted imaging (SigmaScan/SigmaScan Pro software, Jandel Scientific, San Rafael, CA). Measurements were collected at three levels spaced $70 \mu \mathrm{m}$ apart through the portion of the graft containing the greatest number of $\mathrm{TH}^{+}$neurons. Area and density measures of graft-derived innervation were derived from coded microscope slides and made by an observer blind to assignment of experimental groups. Illumination was adjusted to detect only $\mathrm{TH}^{+}$elements. The portion of the caudate nucleus occupied by $\mathrm{TH}^{+}$elements was expressed as percentage of the entire crosssectional area of the caudate at the levels chosen. Fiber density was measured in a $200 \times 300 \mu \mathrm{m}$ field at $100 \times$ magnification, positioned immediately lateral to the graft border in a region judged to represent a zone of maximum fiber density. Fiber density measures were expressed relative to the density of $\mathrm{TH}^{+}$innervation in the contralateral intact striatum.

Statistical analyses. The number of drug-induced rotations across experimental groups over time were analyzed with repeated-measures ANOVA, followed by post hoc Fisher's PLSD test or means comparisons analysis to identify specific comparisons that attained statistical significance. Quantified morphological measures were analyzed with ANOVA followed by post hoc Fisher's PLSD test. Differences in morphological measures between VM grafts and VM-Schwann cell co-grafts for the individual middle-aged and old-aged groups receiving these treatments were assessed with $t$ test.

\section{RESULTS}

\section{Morphology of lesions}

Mesostriatal DA system lesions were uniformly large, providing near-total elimination of $\mathrm{TH}^{+}$soma in the substantia nigra and additional variable loss of $\mathrm{TH}^{+}$cells in the ventral tegmental area (Figure 2). $\mathrm{TH}^{+}$fiber staining in the caudate nucleus ipsilateral to the lesion was eliminated, with staining in the septal area, nucleus accumbens, and olfactory tubercle markedly decreased.
Table 1. Aging-related changes in baseline amphetamine-induced rotational behavior

\begin{tabular}{llll} 
Group & $n$ & Age/lesion duration & $\begin{array}{l}\text { Rotations/ } \\
\min ^{a}\end{array}$ \\
\hline STY & 10 & 4 m.o./1 month & $7.4 \pm 0.86$ \\
STM & 12 & 17 m.o./1 month & $7.4 \pm 0.46$ \\
LTM & 23 & 17 m.o./14 months & $7.3 \pm 0.42$ \\
STO & 15 & 24 m.o./1 month & $4.1 \pm 0.39^{*}, * *$ \\
LTO & 15 & 26 m.o./14 months & $5.6 \pm 0.44^{*}$
\end{tabular}

${ }^{a}$ Expressed as mean \pm SEM.

${ }^{*} p<0.05$ as compared with groups STY, STM, and LTM.

${ }^{* *} p<0.05$ as compared with group LTO.

$F_{(4,70)}=8.92, p<0.001$; Fisher's PLSD post hoc test.

\section{Rotational behavior in rats of varying age and lesion duration}

The rate of rotation to amphetamine before neural grafting differed among rats of varying age and lesion duration. As shown in Table 1, rats in the oldest age groups (24 and 26 m.o.) displayed significantly fewer rotations per minute after amphetamine challenge than middle-aged (17 m.o.) and young (4 m.o.) rats $\left(\right.$ ANOVA $F_{(4,70)}=8.92, p<0.001$; Fisher's PLSD,$\left.p<0.03\right)$. An additional significant difference was found in rotational behavior of old-aged rats with long- versus short-term lesions, with longterm lesion aged rats exhibiting higher rates of rotation (Fisher's PLSD, $p<0.03$ ). These aging-related differences in rotation rate were not attributable to lesion severity. Lesions in all animals were comparable and extensive. Observation of these animals suggested that lower rates of rotation in aged rats was a product of age-related declines in motor function. This interpretation is consistent with previous findings of decreased motor performance in aged rats and has been associated with multiple changes in mesostriatal DA system function (Joseph et al., 1978; Emerich et al., 1993; Hebert and Gerhardt, 1998). For statistical comparisons of graft effects on rotational behavior, rates of rotation for each experimental group were expressed as percentage of their own baseline to adjust for inherent aging-related differences in basal rotation rates.

\section{Behavioral effects of DA grafts in rats of varying age and lesion duration}

Individual analysis of rotational behavior in groups of nongrafted control rats revealed no spontaneous improvement of this behav- 


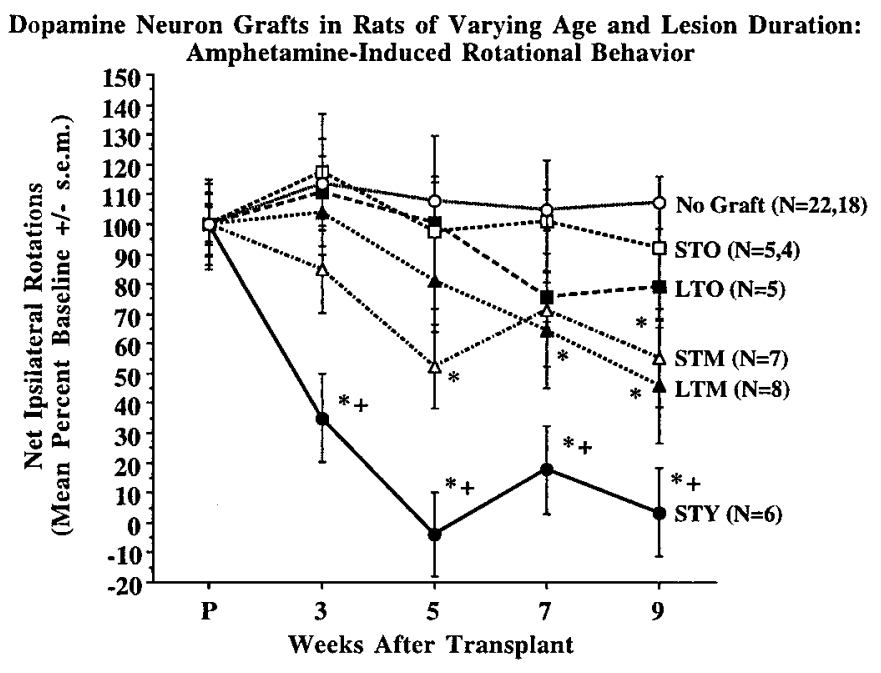

Figure 3. Amphetamine-induced rotational behavior in rats of varying age and lesion duration after implantation of DA neuron grafts. The capacity for graft-derived amelioration of rotational asymmetry decreased in a step-wise manner with increasing age of the host animal at the time of transplant and was not related to duration of DA depletion in the mesostriatal system. Group STY exhibited a statistically significant decline in rotational behavior as compared with their own baseline and all other experimental groups at 3,5,7, and 9 weeks after grafting. Middleaged rats were significantly improved as compared with nongrafted controls at 9 weeks after grafting, and with their own baseline at 5 and 9 weeks for short-term lesions, and 7 and 9 weeks for long-term lesions. Old-aged rats did not exhibit significant graft-derived behavioral recovery as compared with their own baseline or the behavior of nongrafted controls. Group abbreviations are as described in text and Figure 1 legend. Time point $P$ on the $x$-axis designates baseline rotational behavior $\sim 1$ week before grafting. $+p<0.01$ compared with all other groups; ${ }^{*} p<0.01$ compared with baseline and pooled nongrafted control group.

ior in rats of varying age and lesion duration. Accordingly, control animals were pooled, and their composite behavior is represented in Figure 3.

For rats receiving DA neuron implants, graft-related amelioration of amphetamine-induced rotational behavior was markedly diminished in rats of increasing age (Fig. 3). Repeated-measures ANOVA of rats with short-term lesions showed significant effects of age $\left(F_{(3,27)}=17.17, p<0.001\right)$, time after transplant $\left(F_{(4,108)}=\right.$ $4.95, p<0.002)$, and the time $\times$ age interaction $\left(F_{(12,108)}=3.64\right.$, $p<0.001)$. For rats with long-term lesions, analysis indicated significant effects of age $\left(F_{(2,16)}=3.77, p<0.05\right)$ and time after transplant $\left(F_{(4,64)}=3.60, p<0.02\right)$. The time $\times$ age interaction was not significant for long-term as compared with short-term lesions in middle- and old-aged rats $\left(F_{(8,64)}=1.23, p=0.30\right)$. Young rats (4 m.o.) with short-term lesions (group STY) exhibited a significant improvement of rotational behavior by 3 weeks after grafting, and complete reversal of rotational behavior at 5 weeks after grafting and beyond $(p<0.001)$. The behavioral improvement in young rats with short-term lesions was statistically different from all other groups on weeks 3, 5, 7, and 9 after transplant surgery $(p<0.004)$. In contrast, middle-aged rats $(17$ m.o.) with both short- and long-term lesions (groups STM and LTM) exhibited gradual improvement, reaching 45-55\% amelioration of rotational behavior by 9 weeks after grafting. Middleaged rats exhibited significant improvement of rotational behavior compared with nongrafted controls $(p<0.002)$ but were not statistically distinguishable from old-aged rats. Middle-aged rats with short-term lesions showed significant behavioral improve- ment from their own baseline on weeks 5 and 9 after grafting $(p<0.01)$, whereas middle-aged rats with long-term lesions were statistically improved on weeks 7 and $9(p<0.02)$. Rats in the oldest age groups ( 24 and 26 m.o.) with both short- and long-term lesions (groups STO and LTO) exhibited a modest 8-21\% mean improvement at 9 weeks after implantation, and over this time did not attain statistically significant improvement relative to their own baseline rotational behavior or the behavior of nongrafted control animals. This waning behavioral efficacy provided by grafts of identical preparation was primarily related to age of the transplant recipient and not the duration of striatal DA depletion, because within the middle- and old-aged groups significant differences were not detected in the response of animals with lesions in place for 1 month versus 14 months.

\section{Graft morphology}

Morphology of the VM grafts as visualized with TH immunocytochemistry corresponded well to the variations in behavioral efficacy observed in groups of animals of differing age and lesion duration. As illustrated in Figure 4, dispersed cell grafts in young rats with short-term lesions (group STY) were larger, contained clusters of $\mathrm{TH}^{+}$cell bodies, and densely reinnervated the surrounding host striatum. In contrast, implants in aged rats with long- or short-term lesions (groups LTO and STO) remained the approximate size of the needle track, contained relatively few $\mathrm{TH}^{+}$neurons, and contributed sparse reinnervation to the denervated striatum. The morphology of grafts in middle-aged rats with long-term lesions (group LTM) was highly variable, with examples corresponding to the extremes represented by groups STY and LTO present. Grafts in middle-aged rats with shortterm lesions (group STM) were less variable and tended to resemble grafts in old rats.

Quantitative measures of grafted cell survival and reinnervation of the striatum supported the qualitative impressions of graft morphology (Figure 5). Overall size of the implants and $\mathrm{TH}^{+}$ neuron survival was greatest in young rats with short-term lesions (STY) (Fig. 5A,B). Middle-aged rats with long-term lesions (LTM) exhibited a modest, nonsignificant reduction in graft size and DA neuron survival. In contrast, middle-aged rats with shortterm lesions (STM) and aged rats with short- and long-term lesions (STO, LTO) exhibited significantly smaller implants $\left(F_{(4,20)}=8.60, p<0.001\right.$; Fisher's PLSD, $\left.p<0.04\right)$ containing many fewer surviving DA neurons $(-80 \%)\left(F_{(4,21)}=2.83, p=\right.$ 0.05; Fisher's PLSD, $p<0.03$ ).

Measurements of graft-derived innervation followed a somewhat different pattern (Fig. 5C,D). Most notably, although middle-aged rats with long-term lesions exhibited overall graft size and $\mathrm{TH}^{+}$neuron survival comparable to young rats, the area occupied by grafted-derived $\mathrm{TH}^{+}$neurites was significantly reduced in these animals and comparable to rats of the other middle- and old-aged groups (Fig. $5 C)\left(F_{(4,70)}=8.90, p<0.001\right.$; Fisher's PLSD, $p<0.001)$. Grafted $\mathrm{TH}^{+}$neurons and their neurites in young rats with short-term lesions occupied $\sim 20 \%$ of the cross-sectional area of the grafted striatum. In contrast, grafts in all middle- and old-aged groups exhibited a significant decrease in area of potential influence, occupying $<10 \%$ of the coronal area of the striatum. The maximum density of graft-derived innervation adjacent to implants was less variable among groups (Fig. 5D). Although $\mathrm{TH}^{+}$fiber density was highest in young rats with short-term lesions, at $\sim 55 \%$ of the intact complement, innervation in middle- and old-aged rats with long-term lesions was not significantly different, reaching $\sim 40 \%$ of intact density. 

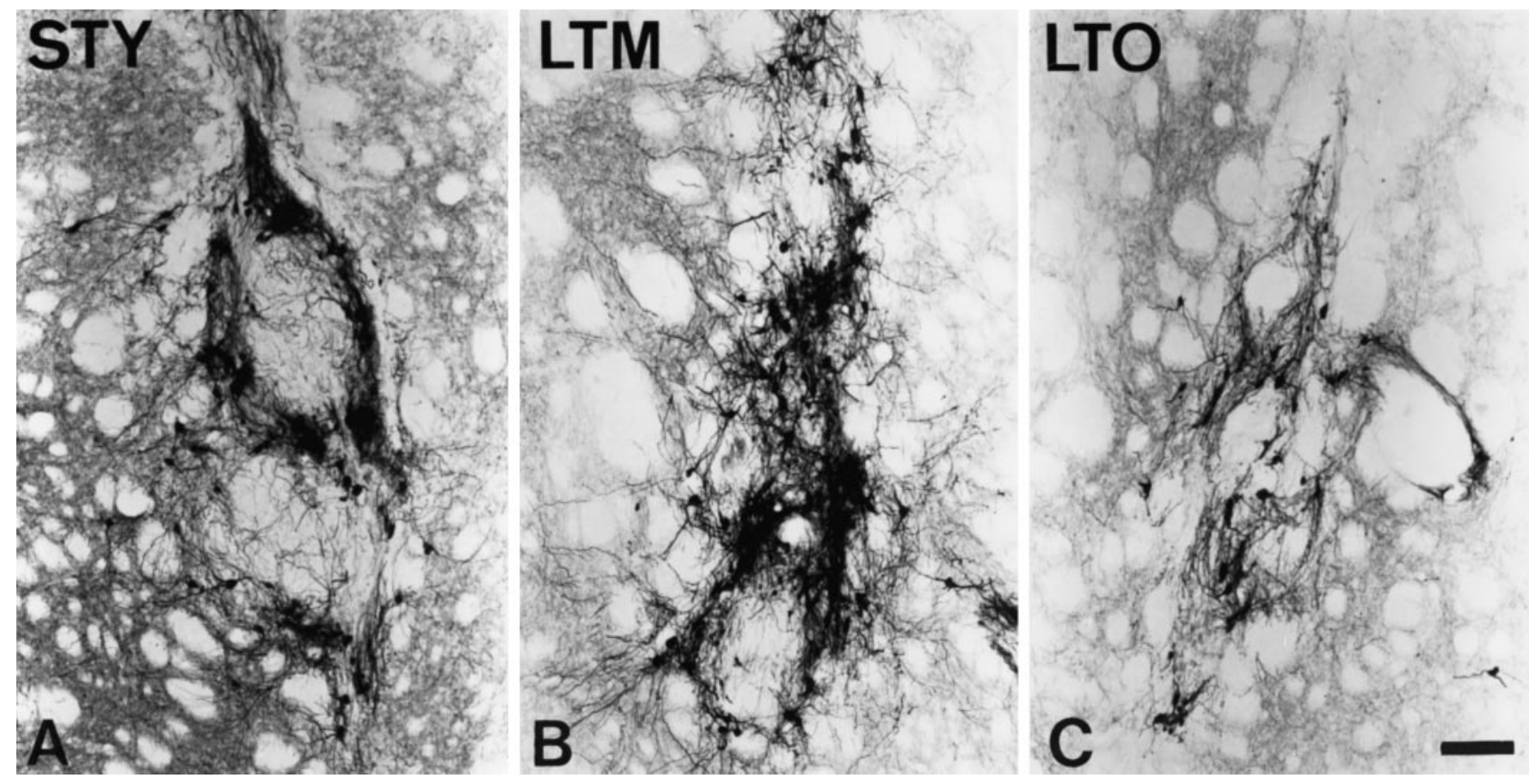

Figure 4. Representative ventral mesencephalic tissue grafts in rats of varying age and lesion duration. Grafts of identical composition are illustrated at 10 weeks after grafting in members of groups STY, LTM, and LTO, as visualized with TH staining. Morphology of grafts is consistent with quantitative measures, indicating that survival of grafted DA neurons is significantly decreased in aged host rats $(C$, group $L T O)$ as compared with young ( $A$, group $S T Y$ ) and middle-aged ( $B$, group $L T M)$ hosts. In contrast, graft-derived innervation of the caudate nucleus is decreased in both middle- and old-aged hosts as compared with young rats. Scale bar, $100 \mu \mathrm{m}$.

However, maximum fiber density was significantly reduced in middle- and old-aged rats with short-term lesions as compared with young rats $\left(F_{(4,73)}=2.72, p<0.04\right.$; Fisher's PLSD, $\left.p<0.03\right)$.

\section{Neurotrophic supplementation with Schwann cell co-grafts}

Co-grafting neonatal rat sciatic nerve Schwann cells with VM tissue improved behavioral recovery in long-term lesion rats and aged rats with short-term lesions (Figure 6). For all three of these groups, co-grafted Schwann cells afforded an additional 31-43\% improvement in amphetamine-induced rotational asymmetry, reaching a statistically significant amelioration in the comparison with DA neuron grafts only for aged rats with short-term lesions (group STO) (repeated-measures ANOVA significant for group, $F_{(2,10)}=4.53, p<0.04$, Fisher's PLSD, $p<0.05$, as compared with nongrafted controls and DA-only implants). Comparisons in middle-aged and aged rats with long-term lesions (groups LTM and LTO) revealed a significant effect of time after transplant (group LTM: $F_{(4,76)}=5.41, p<0.001$; group LTO: $F_{(4,32)}=5.70$, $p<0.002)$. For group LTM this was attributable to DA-grafted and co-grafted rats exhibiting significant improvement from their own baseline on weeks 7 and 9 after grafting $(p<0.02)$, whereas for group LTO, only co-grafted rats exhibited a significant improvement from baseline $(p<0.02)$.

Effects of Schwann cell co-grafts on quantitative measures of VM graft morphology varied among middle- and old-aged groups (Fig. 7). Co-grafts provided little or no improvement of the morphology of VM grafts in middle-aged rats with long-term lesions, and for some measures co-grafted rats exhibited morphological characteristics that were diminished as a group compared with rats with only grafts of VM tissue. In contrast, co-grafts appeared to augment VM graft morphology in old-aged rats.
Although total size of the VM graft exhibited a modest increase (Fig. $7 A$ ), the number of surviving grafted DA neurons was approximately doubled in co-grafted aged rats (Fig. $7 B$ ). This trend did not reach statistical significance. Old rats with co-grafts exhibited a marked increase in cross-sectional area of grafted $\mathrm{TH}^{+}$elements, approximately doubling the potential area of influence of grafted $\mathrm{TH}^{+}$neurons and their innervation (Fig. $7 C)$. This increase was statistically significant for group STO $(t=$ 2.05 , $\mathrm{df}=28, p=0.05$ ), but failed to achieve significance for group LTO $(t=1.74$, df $=28, p=0.09)$. Maximum density of graft-derived fibers exhibited a modest, $\sim 15 \%$, increase in aged co-grafted rats, but with this attained a density comparable to grafts in young rats (Fig. 7D).

Qualitatively, the changes in graft morphology in some cografted aging rats were impressive, equaling or surpassing the best grafts in young rats with short-term lesions (Fig. 8A,B). Variability in the morphology of VM grafts in aged co-grafted rats was large, and we found it difficult to relate this variation to differences in survival of the Schwann cell co-graft. As visualized at 10 weeks after implantation, Schwann cell co-grafts presented a uniform histological appearance. In general, Schwann cell implants were slender, approximating the diameter of the needle track, and appeared as undulating collections of elongated nuclei, reminiscent of the "snake fence" appearance of peripheral nerve in histological sections (Fig. 8C). The impression yielded by histology was that many fewer Schwann cells were surviving at 10 weeks after implantation than would be predicted from the original number implanted. In no case was there any indication of continued growth or expansion of the Schwann cell implant. Thus, histology of the Schwann cell implants at 10 weeks after grafting appeared to be an inadequate index of co-graft viability and function at earlier timepoints. 

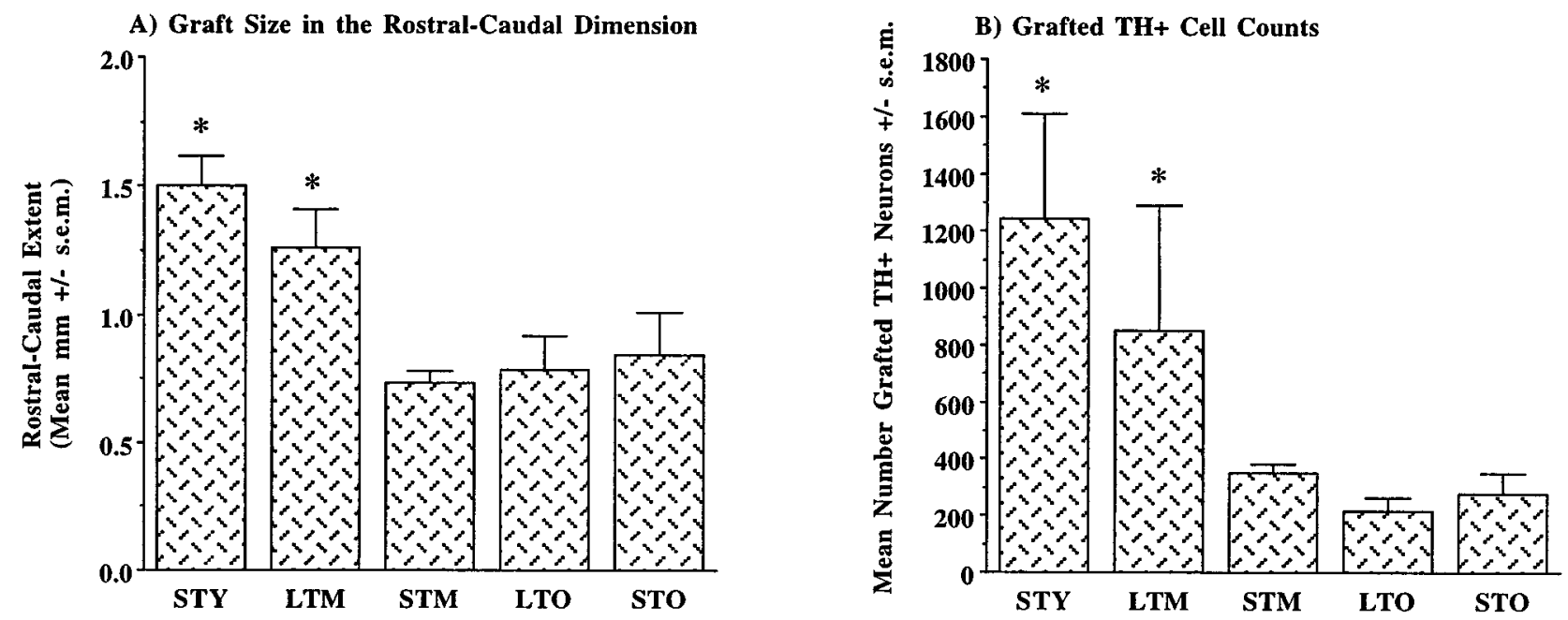

C) Cross-Sectional Area of TH+ Elements

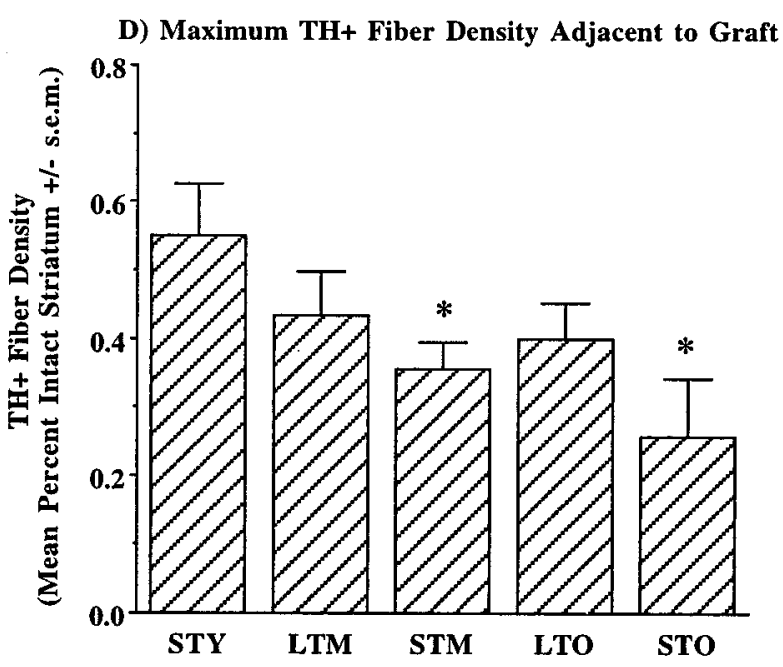

Figure 5. Quantitative measures of DA graft morphology. Measures of graft size $(A)$ and counts of $\mathrm{TH}^{+}$neurons $(B)$ indicated significantly better survival in rats lesioned as young adults (groups $S T Y$ and $L T M$ ) as compared with those lesioned as older animals (STM, STO, LTO). In contrast, area of graft-derived innervation $(C)$ was significantly decreased in all groups of middle- and old-aged rats as compared with young adult animals. The maximum density of graft-derived innervation $(D)$ was significantly decreased only in middle- and old-aged rats with short-term lesions as compared with young animals. Group abbreviations are as presented in Figure 1 legend. The number of measurements per group is as follows. For graft size and TH ${ }^{+}$ cell counts: $S T Y(n=6), S T M(n=6), L T M(n=5), S T O(n=4), L T O(n=5)$; for cross-sectional area of TH ${ }^{+}$elements and maximum fiber density: $\operatorname{STY}(n=18), \operatorname{STM}(n=18), \operatorname{LTM}(n=15), \operatorname{STO}(n=12), \operatorname{LTO}(n=15) .{ }^{*} p<0.04$.

\section{DISCUSSION}

Studies of DA neuron grafting in animals have provided a great deal of information concerning factors associated with the graft itself that yield optimal growth and function (Brundin et al., 1987; Yurek and Sladek, 1990; Olanow et al., 1996). Our interest has shifted to factors associated with the transplant recipient and the environment for grafted DA neurons. In the present study we provide information on two factors that are rarely modeled in animal experiments but are characteristic of the majority of PD patients that could be considered candidates for neural graft therapy: advancing age and a protracted history of striatal DA depletion. Specifically, we compared behavioral and morphological correlates of a standardized VM graft in rats of advancing age with short-term DA depletions with middle- and old-aged male F344 rats with DA depletions in place for 14 months, an interval equivalent to approximately one-half of the mean lifespan of this strain.

Our findings are summarized in Table 2 and are as follows. (1) The capacity for DA neuron grafts to ameliorate amphetamineinduced rotational behavior was reduced with advancing age of the graft recipient. The same graft that provided complete reversal of rotational behavior in young rats with short-term lesions produced $\sim 50 \%$ reduction of this behavior in middle-aged rats and was virtually without therapeutic effect in the oldest animals. (2) The behavioral response to the DA graft was determined by the age of the transplant recipient at the time of grafting and not by the duration of striatal DA depletion. (3) Diminished behavioral effects of grafts were attributable to decreased survival and neurite outgrowth of grafted DA neurons. (4) Behavioral and morphological features of DA grafts in aging rats were enhanced 

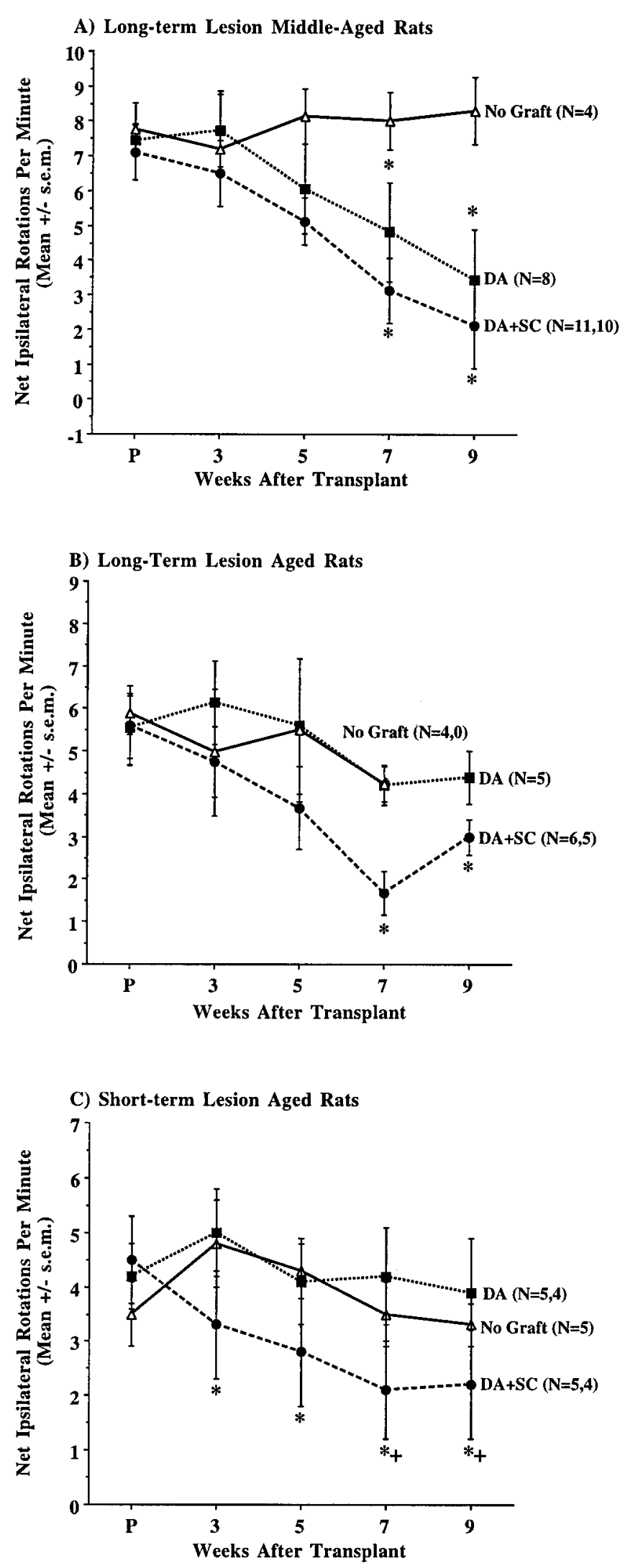

Figure 6. Comparison of amphetamine-induced rotational behavior in middle- and old-aged rats receiving DA neuron grafts or DA neuronSchwann cell co-grafts. Co-grafted Schwann cells improved DA graft outcome in these groups. $A$, For rats in group LTM, co-grafts did not alter the time course of behavioral improvement but enhanced the magnitude by the presence of co-grafted sciatic nerve Schwann cells, a demonstrated source of neurotrophic activity for embryonic DA neurons (Collier et al., 1990; Collier and Springer, 1991; Collier and Martin, 1993).

To the best of our knowledge, the behavioral effects of DA grafts have not been assessed previously in an animal model that combines severe depletion of striatal DA and advanced age. DA neuron grafts have been studied in intact aged rats (Gage et al., 1983a,b). In these experiments, grafts survived adequately but were noted not to grow as large or provide as much reinnervation as grafts in lesioned young rats (Gage et al., 1983a). These differences were attributed to the placement of grafts into the nondenervated striatum. In addition, DA neuron grafts were demonstrated to improve motor coordination in intact aged rats (Gage et al., 1983b). Our findings of reduced survival and neurite extension for DA neurons grafted into aged denervated rats are in general agreement with previous findings, but the design of the current study allows implication of the environment of the aged brain as a contributing factor in this outcome. Similarly, it is not surprising that behavioral improvement has been achieved with grafts placed into the intact aged striatum, but not found in our study. The DA depletion produced by aging alone is less than that produced by lesion of the mesostriatal pathway, affording a better opportunity for graft-related DA replacement to exert a significant behavioral effect. Indeed, our study does not examine whether under optimal conditions (e.g., multiple implants, etc.) DA grafts can be therapeutic in aged, DA-depleted animals. Instead, we have used a suboptimal implant to probe the nature of the aging, DA-depleted striatal environment. Use of a graft that should be marginally effective in young rats allows detection of factors that both impair and augment graft outcome.

The current study focused on the comparison of aging and duration of striatal DA depletion as they influence mechanisms of graft viability and function. It was surprising that for the parameters studied here there was no evidence that duration of DA depletion per se was of significant detriment. Rather, the evidence suggested that chronological age at the time of transplant surgery, or chronological age at the time of lesion, were of primary importance in predicting graft outcomes. For graftrelated amelioration of rotational behavior, age of the graft recipient at the time of transplant exerted the primary effect on behavioral recovery. Within these age groups, no difference in behavioral recovery was detected between rats with DA-depleting lesions in place for 1 month versus 14 months. For morphological measures of graft viability and growth, $\mathrm{TH}^{+}$cell survival and neurite extension appeared to be dissociable, each influenced by different features of the host animal's history. Like behavioral efficacy, the cross-sectional area occupied by grafted $\mathrm{TH}^{+}$neurons and their processes was primarily affected by age of the recipient at time of transplant. Middle-aged rats with long-term lesions were similar to the other groups of middle- and old-aged

of this improvement as compared with DA grafts alone. This augmentation was not statistically significant. Both graft and co-graft groups were significantly improved relative to their baseline on weeks 7 and 9 after grafting. $B$, Repeated-measures ANOVA for aged rats in group LTO revealed no significant effect of group but detected a significant improvement over time compared with baseline rotation only for co-grafted rats. $C$, For rats in group STO, a significant effect of group was detected, attributable to improved performance of co-grafted rats as compared with DA grafts on weeks 7 and 9 after grafting. $+p<0.05$ as compared with DA graft group; ${ }^{*} p<0.05$ as compared with baseline rotation. 
A) Graft Size in Rostral-Caudal Dimension: Co-Grafts

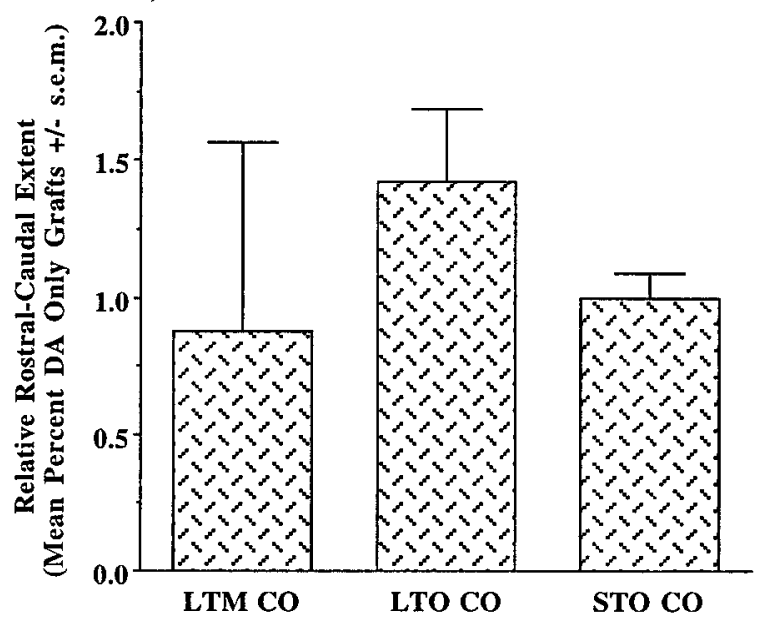

C) Cross-sectional Area TH+ Elements: Co-Grafts

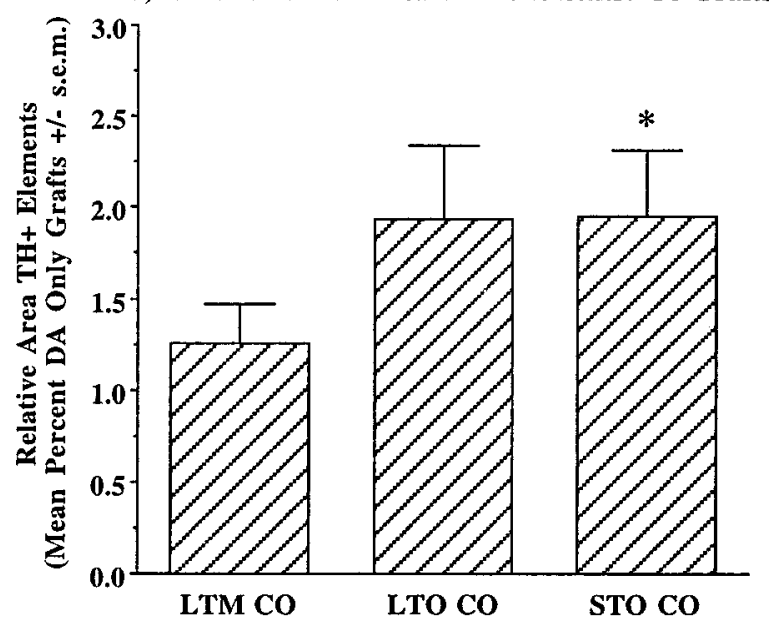

B) TH+ Cell Counts: Co-Grafts

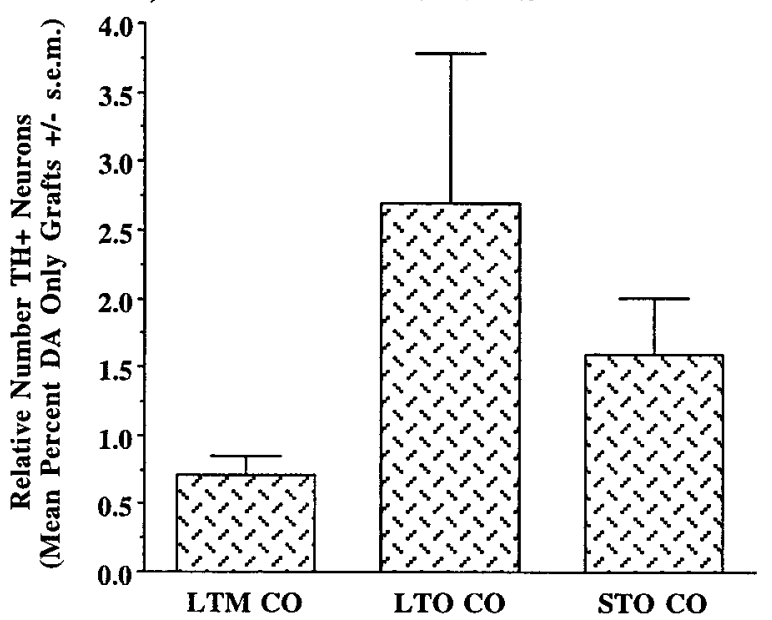

Figure 7. Comparison of quantitative measures of graft morphology in middle- and old-aged rats receiving DA neuron grafts or DA neuron-Schwann cell co-grafts. Values graphed are for co-grafts and expressed as values relative to the same measure for DA neuron grafts in the same host condition. Measures of graft size $(A, B)$ and neurite outgrowth $(C)$ and density $(D)$ were increased in the presence of co-grafted Schwann cells in both groups of old-aged hosts. Although survival of grafted $\mathrm{TH}^{+}$neurons was approximately doubled in aged rats with co-grafts $(B)$, this trend did not reach statistical significance. Similarly, aged rats with co-grafted Schwann cells exhibited an approximate doubling of the area of graft-derived innervation $(C)$, with this change reaching statistical significance for co-grafts in group STO. Group abbreviations are defined in Figure 1 legend. The number of measurements per group is as follows. For graft size and $\mathrm{TH}^{+}$cell counts: $L T M C O(n=9), S T O C O(n=6), L T O C O(n=6)$; for cross-sectional area of TH ${ }^{+}$elements and fiber density: $\operatorname{LTMCO}(n=27)$, STO CO $(n=18), \operatorname{LTO} C O(n=18) .{ }^{*} p=0.05$.

animals, exhibiting a statistically significant reduction of area of grafted neurons and innervation compared with young rats. Maximum density of graft-derived innervation followed a similar pattern, but changes were of lesser magnitude. All middle- and old-aged rats exhibited modest decreases compared with young rats. In contrast, survival of grafted DA neurons was primarily influenced by age of the host at the time of lesion. Young rats with short-term lesions and middle-aged rats with long-term lesions exhibited significantly larger grafts containing greater numbers of surviving $\mathrm{TH}^{+}$neurons. Both of these groups received their mesostriatal lesions as young adults (3 m.o.). All groups that were lesioned at 12 m.o. or older exhibited comparable, reduced overall graft sizes and $\mathrm{TH}^{+}$neuron survival.

It is our working hypothesis that the pattern of behavioral and morphological effects seen in these animals are a reflection of aging- and lesion-related changes in the striatal neurotrophic environment. Both maturation and DA-depleting lesions are known to affect the abundance of identified growth factors for DA neurons present in the striatum (Collier and Sortwell, 1999): a decreasing prevalence in adulthood (Wilcox and Derynck, 1988; Schaar et al., 1993; Seroogy et al., 1993; Stromberg et al., 1993; Choi-Lundberg and Bohn, 1995; Nosrat et al., 1996; Kornblum et al., 1997; Widenfalk et al., 1997) yet capable of induction after mesostriatal lesion (Chadi et al., 1994; Funa et al., 1996). The abundance and activity of identified DA neurotrophic molecules in aging brain is unknown. However, two studies have examined the general capacity for neurotrophic responses in the aged striatum. Kaseloo and colleagues (1996) collected extracts from biopsy sites in striatum of otherwise intact young (2-3 m.o.) and aged (18-24 m.o.) rats and assayed them for neurotrophic activity 

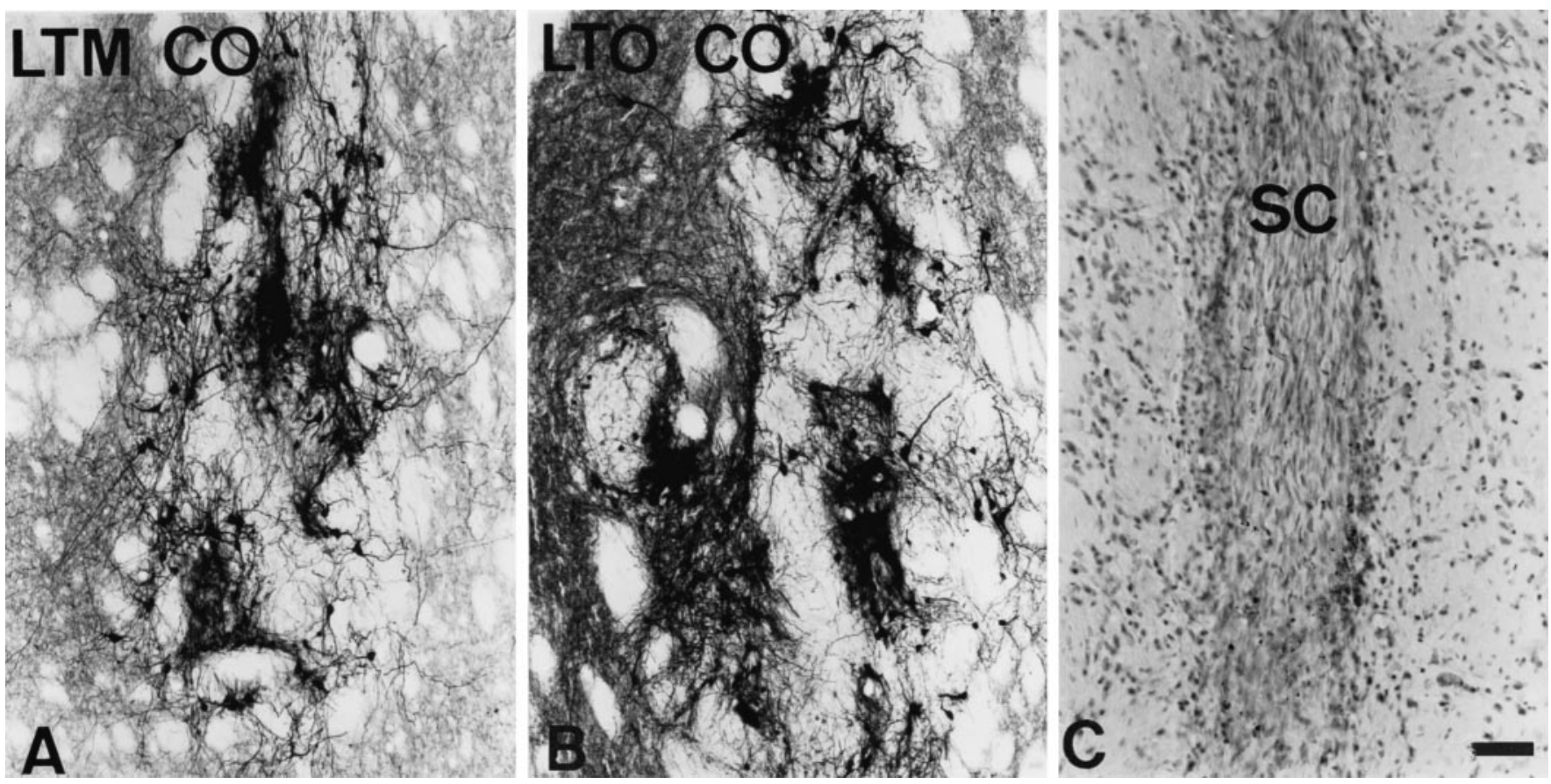

Figure 8. Representative morphology of ventral mesencephalic tissue co-grafted with Schwann cells in aging rats and morphology of co-grafted Schwann cells. $A, B$, Graft-derived $\mathrm{TH}^{+}$innervation was increased in the presence of co-grafted Schwann cells, accompanied by an approximate doubling of survival of grafted $\mathrm{TH}^{+}$neurons in the oldest rats. $C$, Schwann cell co-grafts were detectable in Nissl-stained sections as compact collections of undulating nuclei, typical of the appearance of peripheral nerve in histological sections and distinct from the morphology of the surrounding striatum. LTM CO, Long-term lesioned middle-aged rat with co-graft; $L T O C O$, long-term lesioned old-aged rat with co-graft; SC, Schwann cells. Scale bar (shown in $C): A, B, 100 \mu \mathrm{m} ; C, 50 \mu \mathrm{m}$.

Table 2. Summary of results

Percent of measures for group STY

\begin{tabular}{llllll} 
Group & Rotation & Graft size & $\mathrm{TH}^{+}$cells & Fiber extent & Fiber density \\
\hline STY & $-96.5^{a}$ & 100 & 100 & 100 & 100 \\
LTM & $-53.8^{a}$ & 83.7 & 68.3 & $44.7^{b}$ & 78.2 \\
STM & $-44.7^{a}$ & $48.8^{b}$ & $28.2^{b}$ & $32.2^{b}$ & $64.6^{b}$ \\
STO & -21.0 & $55.8^{b}$ & $22.2^{b}$ & $29.7^{b}$ & $46.5^{b}$ \\
LTO & -7.8 & $52.3^{b}$ & $17.3^{b}$ & $28.1^{b}$ & 72.7 \\
LTM-CO & $-70.1^{a}$ & $71.3^{b}$ & $48.8^{b}$ & $57.3^{b}$ & $57.3^{b}$ \\
STO-CO & $-51.3^{a, c}$ & $55.8^{b}$ & $35.4^{b}$ & $58.0^{b, c}$ & $52.0^{b}$ \\
LTO-CO & $-46.7^{a, c}$ & $74.4^{b}$ & $46.5^{b}$ & $54.3^{b}$ & 81.8 \\
\hline
\end{tabular}

${ }^{a}$ Significantly different from rotation before grafting.

${ }^{b}$ Significantly different from STY.

${ }^{c}$ Significantly different from non-co-grafted group.

in cultures of the DA-producing SH-SY5Y cell line. Extract from aged rats exhibited significantly reduced neurite-promoting activity but maintained neuroprotective activity. Our own recent work with Carvey and colleagues (Ling et al., 1998) indicated that neurotrophic extracts from the striatum of 18 and 23 m.o. rats exhibited reduced survival- and neurite-promoting activity for cultured embryonic rat $\mathrm{VM} \mathrm{TH}^{+}$neurons as compared with striatal extracts from rats at 4 and 12 m.o. In addition, although striatal-derived neurotrophic activity was significantly increased ipsilateral to mesostriatal system lesion in younger rats, this reactive compensation was absent in aging animals. Within this context, the observations of the current report support the view that DA grafts implanted into middle- and old-aged hosts are likely to encounter an impoverished striatal neurotrophic envi- ronment that may contribute to decreased graft viability and function. The one exception to this view is the better survival of grafted DA neurons in middle-aged rats lesioned as young adults. This finding may suggest that striatal factors important for survival of grafted neurons may undergo long-lasting upregulation after denervation in young rats and that a residue of neurotrophic induction may persist in middle-aged rats that were lesioned as young animals.

One prediction of the hypothesis that diminished graft viability and function in aging hosts is a product of an impoverished striatal neurotrophic environment is that local neurotrophic supplementation would improve DA graft outcome. The present study demonstrates that this is the case. We have demonstrated previously that segments of peripheral nerve, Schwann cells, and 
Schwann cell conditioned medium provide survival- and neuritepromoting activity for embryonic DA neurons in culture (Collier et al., 1990; Collier and Martin, 1993) and in neural grafts (Collier and Springer, 1991). In the present study, co-grafted Schwann cells provided augmentation of behavioral and morphological features of DA grafts in aged hosts. Although the augmentation provided by Schwann cell co-grafts leaves room for improvement, the presence of activity for both survival and neurite extension of grafted neurons suggests the presence of multiple neurotrophic molecules provided by co-grafted Schwann cells. Given these effects, further experimentation manipulating the number, placement, and survival of grafted Schwann cells is warranted.

In summary, the findings of the present report indicate that advancing chronological age of the transplant recipient may be an underappreciated risk factor for poor outcome after intrastriatal implantation of embryonic DA neurons. Duration of striatal DA depletion was of less importance in determining graft outcome. Parameters of graft outcome were differentially sensitive to age of the host at the time of the DA-depleting lesion and at the time of transplant. By analogy, age of the PD patient at disease onset and at the time of transplant therapy may critically affect graft outcome, favoring a better prognosis for younger patients that are earlier in the progression of their disease. The available evidence is consistent with the view that the aged DA-depleted striatum represents an impoverished neurotrophic environment for grafted DA neurons, contributing directly to reduced graft viability and function. However, co-grafted Schwann cells were capable of providing local neurotrophic supplementation, resulting in better survival, neurite extension, and behavioral efficacy of grafted DA neurons in hosts of advanced age. Taken together, these results provide an argument that favors the development of adjunct therapies to supplement the neurotrophic environment of grafted DA neurons to achieve optimal therapeutic effects in elderly patients with PD.

Note added in proof. Dr. C. R. Freed (University of Colorado Health Science Center, Denver, CO) and colleagues recently reported results of their clinical trial of fetal DA neuron grafting for PD (presentation, American Academy of Neurology conference, Toronto, Ontario, Canada, April 21, 1999; New York Times, April 22, 1999; presentation, American Society for Neural Transplantation and Repair conference, Clearwater, FL, April 30, 1999). One of the factors studied was the relationship between age of the transplant recipient and clinical outcome. Consistent with the present report, only patients under 60 years of age exhibited statistically significant clinical benefit after grafting, whereas older patients were not helped overall.

\section{REFERENCES}

Brundin P, Strecker RE, Lindvall O, Isacson O, Nilsson OG, Bardin G, Prochiantz A, Forni C, Nieoullon A, Widner H, Gage FH, Bjorklund A (1987) Intracerebral grafting of dopamine neurons. Ann NY Acad Sci 495:473-496.

Chadi G, Cao Y, Pettersson RF, Fuxe K (1994) Temporal and spatial increase of astroglial basic fibroblast growth factor synthesis after 6-hydroxydopamine-induced degeneration of the nigrostriatal dopamine neurons. Neuroscience 61:891-910.

Choi-Lundberg DL, Bohn MC (1995) Ontogeny and distribution of glial cell line-derived neurotrophic factor (GDNF) mRNA in rat. Dev Brain Res 85:80-88.

Collier TJ, Springer JE (1991) Co-grafts of embryonic dopamine neurons and adult sciatic nerve into the denervated striatum enhance behavioral and morphological recovery in rats. Exp Neurol 114: 343-350.

Collier TJ, Martin PN (1993) Schwann cells as a source of neurotrophic activity for dopamine neurons. Exp Neurol 124:129-133.

Collier TJ, Sortwell CE (1999) Therapeutic potential of nerve growth factors in Parkinson's disease. Drugs Aging 14:261-287.

Collier TJ, Sladek CD, Gallagher MJ, Gereau IV RW, Springer JE (1990) Diffusible factor(s) from adult rat sciatic nerve increases cell number and neurite outgrowth of cultured embryonic ventral mesencephalic tyrosine hydroxylase-positive neurons. J Neurosci Res 27:394-399.

Emerich DF, McDermott P, Krueger P, Banks M, Zhao J, Marszalkowski J, Frydel B, Winn SR, Sanberg PR (1993) Locomotion of aged rats: relationship to neurochemical but not morphological changes in nigrostriatal dopaminergic neurons. Brain Res Bull 32:477-486.

Freed CR, Breeze RE, Rosenberg NL, Schneck SA, Kriek E, Qi JX, Lone T, Zhang YB, Snyder JA, Wells TH (1992) Survival of implanted fetal dopamine cells and neurologic improvement 12 to 46 months after transplantation for Parkinson's disease. N Engl J Med 327:1549-1555.

Freeman TB, Olanow CW, Hauser RA, Nauert GM, Smith DA, Borlongan CV, Sanberg PR, Holt DA, Kordower JH, Vingerhoet AB (1995) Bilateral fetal nigral transplantation into the postcommissural putamen in Parkinson's disease. Ann Neurol 38:379-388.

Funa K, Yamada N, Brodin G, Pietz K, Ahgren A, Wictorin K, Lindvall O, Odin P (1996) Enhanced synthesis of platelet-derived growth factor following injury induced by 6-hydroxydopamine in rat brain. Neuroscience 74:825-833.

Gage FH, Bjorklund A, Stenevi U, Dunnett SB (1983a) Intracerebral grafting of neuronal cell suspensions. VIII. Survival and growth of implants of nigral and septal cell suspensions in intact brains of aged rats. Acta Physiol Scand [Suppl] 522:67-75.

Gage FH, Dunnett SB, Stenevi U, Bjorklund A (1983b) Aged rats: recovery of motor impairments by intrastriatal nigral grafts. Science 221:966-969.

Hebert MA, Gerhardt GA (1998) Normal and drug-induced locomotor behavior in aging: comparison to evoked DA release and tissue content in Fischer 344 rats. Brain Res 797:42-54.

Joseph JA, Berger RE, Engel BT, Roth GS (1978) Age-related changes in the nigrostriatum: a behavioral and biochemical analysis. J Gerontol 33:643-649.

Joseph JA, Filburn CR, Roth GS (1981) Development of dopamine receptor denervation supersensitivity in the neostriatum of the senescent rat. Life Sci 29:575-584.

Kaseloo PA, Lis A, Asada H, Barone TA, Plunkett RJ (1996) In vitro assessment of neurotrophic activity from the striatum of aging rats. Neurosci Lett 218:157-160.

Kordower JH, Freeman TB, Snow BJ, Vingerhoets FJ, Mufson EJ, Sanberg PR, Hauser RA, Smith DA, Nauert GM, Perl DP (1995) Neuropathological evidence of graft survival and striatal reinnervation after the transplantation of fetal mesencephalic tissue in a patient with Parkinson's disease. N Engl J Med 332:1118-1124.

Kordower JH, Rosenstein JM, Collier TJ, Burke MA, Chen EY, Li JM, Martel L, Levey AE, Mufson EJ, Freeman TB, Olanow CW (1996) Functional fetal nigral grafts in a patient with Parkinson's disease: chemoanatomic, ultrastructural, and metabolic studies. J Comp Neurol 370:203-230.

Kornblum HI, Hussain RJ, Bronstein JM, Gall CM, Lee DC, Seroogy KB (1997) Prenatal ontogeny of the epidermal growth factor receptor and its ligand, transforming growth factor alpha, in the rat brain. J Comp Neurol 380:243-261.

Ling ZD, Collier TJ, Sortwell CE, Daley BF, Lipton JW, Vu T, Robie HC, Carvey PM (1998) Striatal-derived neurotrophic activity is reduced in the aged rat brain. Soc Neurosci Abstr 24:1947.

Memo M, Lurchi L, Spano PF, Trabucchi M (1980) Aging process affects a single class of dopamine receptors. Brain Res 202:488-492.

Misra CH, Shelat H, Smith RC (1981) Influence of age on the effects of chronic fluphenazine on receptor binding in rat brain. Eur J Pharmacol 76:317-324.

Morgan DG, Finch CE (1988) Dopaminergic changes in the basal ganglia. A generalized phenomenon of aging in mammals. Ann NY Acad Sci 515:145-160.

Nosrat CA, Tomac A, Lindqvist E, Lindskog S, Humpel C, Stromberg I, Ebendal T, Hoffer BJ, Olson L (1996) Cellular expression of GDNF 
mRNA suggests multiple functions inside and outside the nervous system. Cell Tissue Res 286:191-207.

Olanow CW, Kordower JH, Freeman TB (1996) Fetal nigral transplantation as a therapy for Parkinson's disease. Trends Neurosci 19:102-109.

Paxinos G, Watson C (1986) The rat brain in stereotaxic coordinates. San Diego: Academic.

Ponzio F, Calderini G, Lomuscio G, Vantini G, Toffano G, Algeri S (1982) Changes in monoamines and their metabolite levels in some brain regions of aged rats. Neurobiol Aging 3:23-29.

Schaar DG, Sieber B-A, Dreyfus CF, Black IB (1993) Regional and cell-specific expression of GDNF in rat brain. Exp Neurol 124:368-371.

Seroogy KB, Lundgren KH, Lee DC, Guthrie KM, Gall CM (1993) Cellular localization of transforming growth factor-alpha mRNA in rat forebrain. J Neurochem 60:1777-1781.

Spencer DD, Robbins RJ, Naftolin F, Marek KL, Vollmer T, Leranth C, Roth RH, Price LH, Gjedde A, Bunney BS (1992) Unilateral transplantation of human fetal mesencephalic tissue into the caudate nucleus of patients with Parkinson's disease. N Engl J Med 327:1541-1548.

Stromberg I, Bjorklund L, Johansson M, Tomac A, Collins F, Olson L, Hoffer B, Humpel C (1993) Glial cell line-derived neurotrophic factor is expressed in the developing but not adult striatum and stimulates developing dopamine neurons in vivo. Exp Neurol 124:401-412.

Strong R, Samorajski T, Gottesfeld Z (1982) Regional mapping of neos- triatal neurotransmitter systems as a function of aging. J Neurochem 39:831-836.

Valerio A, Belloni M, Gorno ML, Tinti C, Memo M, Spano P (1994) Dopamine D2, D3, and D4 receptor mRNA levels in rat brain and pituitary during aging. Neurobiol Aging 15:713-719.

Widenfalk J, Nosrat C, Tomac A, Westphal H, Hoffer B, Olson L (1997) Neurturin and glial cell line-derived neurotrophic factor receptor-beta (GDNFR-beta), novel proteins related to GDNF and GDNF-alpha with specific cellular patterns of expression suggesting roles in the developing and adult nervous system and in peripheral organs. J Neurosci 17:8506-8519.

Widner H, Tetrud J, Rehncrona S, Snow B, Brundin P, Gustavi B, Bjorklund A, Lindvall O, Langston JW (1992) Bilateral fetal mesencephalic grafting in two patients with parkinsonism induced by 1-methyl-4-phenyl-1,2,3,6-tetrahydropyridine (MPTP). New Engl J Med 327:1556-1563.

Wilcox JN, Derynck R (1988) Localization of cells synthesizing transforming growth factor-alpha mRNA in the mouse brain. J Neurosci 8:1901-1904

Yurek DM, Sladek Jr JR (1990) Dopamine cell replacement: Parkinson's disease. Annu Rev Neurosci 13:415-440.

Yurek DM, Hipkens SB, Hebert MA, Gash DM, Gerhardt GA (1998) Age-related decline in striatal dopamine release and motoric function in brown Norway/Fischer 344 hybrid rats. Brain Res 791:246-256. 